\title{
BMJ Open Prehospital factors associated with death on hospital arrival after traffic crash in Japan: a national observational study
}

\author{
Yusuke Katayama, ${ }^{1}$ Tetsuhisa Kitamura, ${ }^{2}$ Kosuke Kiyohara, ${ }^{3}$ Junya Sado, ${ }^{4}$ \\ Tomoya Hirose, ${ }^{5}$ Tasuku Matsuyama, ${ }^{6}$ Takeyuki Kiguchi, ${ }^{7}$ Junichi Izawa, ${ }^{8}$ \\ Yuko Nakagawa, ${ }^{1}$ Takeshi Shimazu ${ }^{1}$
}

To cite: Katayama Y, Kitamura T, Kiyohara K, et al. Prehospital factors associated with death on hospital arrival after traffic crash in Japan: a national observational study. BMJ Open 2019;9:e025350. doi:10.1136/ bmjopen-2018-025350

- Prepublication history and additional material for this paper are available online. To view these files, please visit the journal online (http://dx.doi. org/10.1136/bmjopen-2018025350).

Received 11 July 2018 Revised 4 October 2018 Accepted 28 November 2018

D) Check for updates

(C) Author(s) (or their employer(s)) 2019. Re-use permitted under CC BY-NC. No commercial re-use. See rights and permissions. Published by BMJ.

For numbered affiliations see end of article.

\section{Correspondence to}

Dr Yusuke Katayama; orion13@hp-emerg.med.osakau.ac.jp

\section{ABSTRACT}

Objective Although it is important to assess prehospital factors associated with traffic crash fatalities to decrease them as a matter of public health, such factors have not been fully revealed.

Methods Using data from the Japanese Trauma Data Bank, a large hospital-based trauma registry in Japan, we retrospectively analysed traffic crash patients transported to participating facilities that treated patients with severe trauma from 2004 to 2015. This study defined registered emergency patients whose systolic blood pressure was $0 \mathrm{~mm} \mathrm{Hg}$ or heart rate was $0 \mathrm{bpm}$ at hospital arrival as being in prehospital cardiopulmonary arrest (CPA). Prehospital factors associated with prehospital CPA due to traffic crash were assessed with multivariable logistic regression analysis.

Results In total, 66243 patients were eligible for analysis. Of them, 3390 (5.1\%) patients were in CPA at hospital arrival. A multivariable logistic regression model showed the following factors to be significantly associated with prehospital CPA: ages 60-74 years (adjusted OR (AOR) $1.256,95 \% \mathrm{Cl} 1.142$ to 1.382 ) and $\geq 75$ years (AOR 1.487 , $95 \% \mathrm{Cl} 1.336$ to 1.654 ), male sex (AOR $1.234,95 \% \mathrm{Cl}$ 1.139 to 1.338 ), night-time (AOR $1.575,95 \% \mathrm{Cl} 1.458$ to 1.702), weekend including holiday (AOR $1.078,95 \% \mathrm{Cl}$ 1.001 to 1.161), rural area (AOR 1.181, 95\% $\mathrm{Cl} 1.097$ to 1.271), back seat passenger (AOR 1.227, 95\% Cl 0.985 to 1.528) and pedestrian (AOR $1.754,95 \% \mathrm{Cl} 1.580$ to 1.947) as types of patients.

Conclusion In this population, factors associated with prehospital CPA due to a traffic crash were elderly people, male sex, night-time, weekend/holiday, back seat passenger, pedestrian and rural area. These fundamental data may be of help in reducing and preventing traffic crash deaths.

\section{INTRODUCTION}

Recently, the number of casualties due to traffic crash has been decreasing in accordance with the decreasing number of traffic crashes themselves in Japan, ${ }^{1}$ and traffic crash mortality per 100000 habitants was also lower in Japan than in other Organisation
Strengths and limitations of this study

- This study assessed the relationship between cardiopulmonary arrest at hospital arrival due to traffic crash and prehospital factors such as demographic and patient factors with a nationwide hospital-based trauma registry in Japan.

- Elderly, night-time, weekend including holiday, rural area and type of patients such as back seat passenger and pedestrian were associated with prehospital cardiopulmonary arrest due to traffic crash in this study. This study also showed that the types of victims of traffic crashes were different between urban and rural areas.

- This study was not a population-based observation regarding traffic injuries but was conducted based on a multicentre hospital-based trauma registry. Therefore, there might be differences in the results between participating and non-participating hospitals.

- This trauma registry did not obtain information on crash situations such as highway type, weather, road conditions or use of safety devices such as helmets and seatbelts.

for Economic Co-operation and Development member countries. ${ }^{2}$ However, a previous study revealed that youth and the poor were associated with fatal traffic crash deaths in developed countries, ${ }^{3}$ and the number of casualties due to traffic crash has been increasing among the elderly in Japan. ${ }^{4}$ Therefore, it is an important public health problem to assess in detail the factors associated with traffic crash casualties to further decrease and prevent them.

Traffic crash deaths can be divided into either prehospital death at the scene and immediately after hospital arrival or in-hospital death after hospitalisation. In-hospital deaths would be influenced by such factors such as the quality of treatment and medical 
insurance in each country, whereas prehospital death from traffic crashes would be affected by factors relating to the traffic crash itself and/or the type of emergency medical system in each area. ${ }^{5}$ Although we previously reported some factors associated with prehospital traffic crash deaths in urban areas of Japan, ${ }^{6}$ it is still unclear whether regional factors and details of the types of traffic crash patients are associated with prehospital traffic crash deaths.

The Japanese Trauma Data Bank (JTDB) is a nationwide trauma registry in Japan that is managed by The Japanese Association for The Surgery of Trauma. Data registration in the JTDB was launched in 2003, and approximately 230000 emergency patients with trauma were enrolled by $2015 .^{7}$ With the use of data from the JTDB registry, the aim of this study was to evaluate the association of prehospital cardiopulmonary arrest (CPA) due to traffic crash with detailed prehospital factors such as age, sex, regional factors and types of traffic crash patients.

\section{METHODS}

\section{Study design, population and setting}

This study was a retrospective observational study that used the data of emergency trauma patients registered in the JTDB. The study period was the 12-year period between January 2004 and December 2015. From the JTDB registry, we extracted patients with trauma who were injured by traffic crash and were then transported to a JTDB-participating hospital, were registered in the database, and whose information on sex, age, time of day, day of the week, prefectural area of the traffic crash, involvement of an emergency life-saving technician and type of patients was also available. In this study, patients were divided into the following five age categories: $0-14$ years, $15-29$ years, $30-59$ years, $60-74$ years and $\geq 75$ years. As for registered area, Tokyo, Kanagawa, Aichi, Kyoto, Osaka and Hyōgo prefectures were defined as urban areas, and other prefectures were defined as rural areas based on the Japanese legal definition. ${ }^{8}$ The involvement of an emergency life-saving technician was divided into three groups (yes, no and unknown). This study defined daytime as 9:00-17:59 and night-time as 18:00-8:59. In addition, this registry classified the type of patients into car driver, front seat passenger, back seat passenger, and motorcycle rider, pillion passenger, bicyclist, pedestrian and other vehicle passenger.

Personal identifiers had already been removed from the JTDB registry, and thus, patient informed consent was waived.

\section{Japanese Trauma Data Bank}

The JTDB was launched in 2003 by the Japanese Association for the Surgery and Trauma (Trauma Surgery Committee) and the Japanese Association for Acute Medicine (Committee for Clinical Care Evaluation) ${ }^{79}$ similar to trauma databases in North America, Europe and Oceania. ${ }^{10}$ In 2016, the 256 major emergency medical institutions across Japan participated in the JTDB registry. ${ }^{7}$ These hospitals basically have an ability equivalent to the level I trauma centres in the USA. Data were collected via the internet from participating institutions. In most cases, the physicians and medical assistants who attended the Abbreviated Injury Scale (AIS) coding course registered the patients' data. ${ }^{10}$

The JTDB captures data of patients with trauma that includes age, sex, mechanism of injury, AIS code (version 1998), Injury Severity Score (ISS), vital signs on hospital arrival, date and time series from hospital arrival to discharge, medical treatments such as interventional radiology, surgical operation and CT scanning, complications, and mortality at discharge. ${ }^{11}$ The ISS was calculated from the top three scores of the AIS in the nine anatomical regions classified by the AIS code.

\section{Endpoint}

The main endpoint was prehospital CPA in traffic crash patients. This study defined the patients whose systolic blood pressure was $0 \mathrm{~mm} \mathrm{Hg}$ or heart rate was $0 \mathrm{bpm}$ on hospital arrival as being in prehospital CPA.

\section{Statistical analysis}

We divided traffic crash patients into two groups, the patients in CPA at hospital arrival (prehospital CPA group) and the patients alive at hospital arrival (alive group), and assessed prehospital characteristics between the two groups with the $\chi^{2}$ test for categorical variables and Wilcoxon signed-rank test for continuous variables. We calculated the adjusted OR (AOR) and 95\% CI with the use of multivariable logistic regression analysis to assess the factors associated with prehospital CPA by traffic crash. The potential factors were age group (five categories), sex (male, female), time of day (daytime/night-time), day of week (weekday/weekend including holiday), type of patients (described above) and time interval from ambulance call to hospital arrival. Furthermore, we described the proportion of CPA patients at hospital arrival among males and females according to various variables and also calculated crude OR and AOR of male sex versus female sex. In addition, we assessed the factors associated with prehospital CPA by traffic crash patients according to the type of area (urban, rural) as a subgroup analysis. We also divided the study subjects into two groups for further subgroup analysis: elderly patients aged $\geq 65$ years and young patients aged $<65$ years. All tests were two tailed, and a $p<0.05$ was considered statistically significant. Statistical analysis was performed with SPSS V.22.0J (IBM). This manuscript was written based on the Strengthening the Reporting of Observational Studies in Epidemiology statement to assess the reporting of cohort and cross-sectional studies. ${ }^{12}$

\section{Patient and public involvement}

Neither patients nor the public were involved in this study.

\section{RESULTS}

Figure 1 shows the patient flow in this study. In total, 226698 emergency patients were registered in the JTDB 


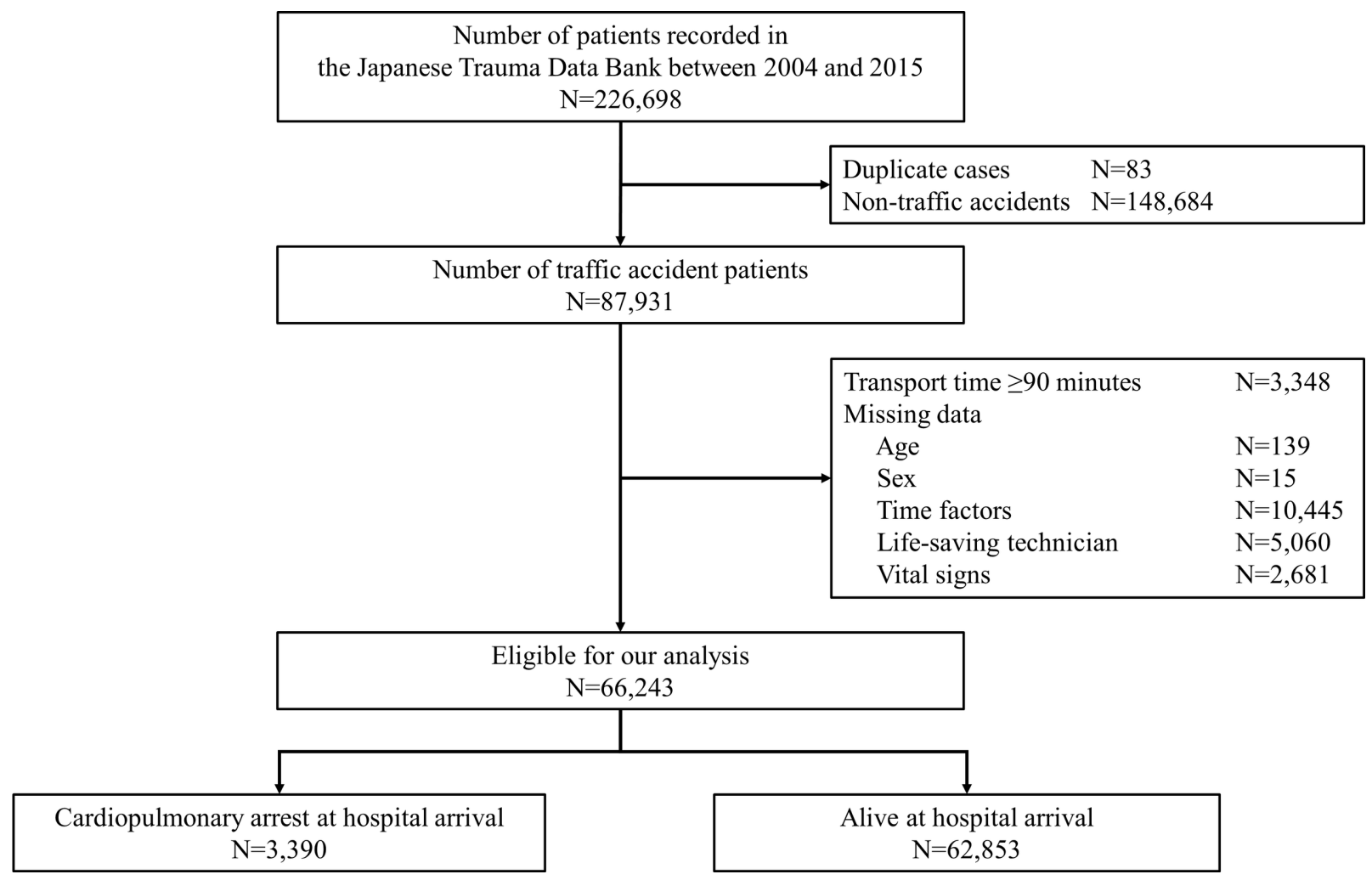

Figure 1 Patient overview in this study.

from 2004 to 2015, and 87931 patients had injuries caused by a traffic crash. Of these patients, 66243 were eligible for our analysis, after excluding 21688 patients with missing data on age $(n=139)$, sex $(n=15)$, involvement of a life-saving technician $(\mathrm{n}=5060)$, vital signs at hospital arrival $(\mathrm{n}=2681)$ and time factors $(\mathrm{n}=10445)$, and those whose transport time to hospital was over $90 \mathrm{~min}$ $(\mathrm{n}=3348)$. Among the remaining patients, 3390 patients (5.1\%) were in CPA at hospital arrival and 62853 (94.9\%) patients were alive at hospital arrival.

Characteristics of the two groups are listed in table 1. No statistically significant difference in sex was revealed between the groups. Compared with the alive group, the prehospital CPA group was more likely to be older and have a crash occurrence at night. As for the type of traffic crash patients, the proportion of bicyclists was lower in the CPA group than in the alive group, but that of pedestrians was higher in the CPA group than in the alive group. The time interval from ambulance call to hospital arrival was shorter in the CPA group than in the alive group.

Factors associated with prehospital CPA due to traffic crash by multivariable logistic regression analysis are shown in table 2. The elderly, 60-74 years (AOR 1.252, $95 \%$ CI 1.138 to $1.377, \mathrm{p}<0.001$ ) and $\geq 75$ years (AOR $1.476,95 \%$ CI 1.327 to $1.642, \mathrm{p}<0.001$ ), male sex (AOR $1.240,95 \%$ CI 1.144 to $1.344, \mathrm{p}<0.001$ ), night-time (AOR $1.581,95 \%$ CI 1.463 to $1.707, \mathrm{p}<0.001)$ and weekend including holiday (AOR 1.077, 95\% CI 1.000 to 1.160 , $\mathrm{p}=0.051$ ) were positively associated with prehospital CPA due to traffic crash. Compared with patients in urban areas, the AOR for those in rural areas was $1.192(95 \%$
CI 1.107 to $1.283, \mathrm{p}<0.001)$. In contrast, the young, $0-14$ years (AOR $0.598,95 \%$ CI 0.495 to $0.722, \mathrm{p}<0.001$ ) and 15-29 years (AOR 0.762, 95\% CI 0.688 to 0.845 , $\mathrm{p}<0.001)$ were negatively associated with prehospital CPA. As for type of patients, compared with car driver, back seat passenger (AOR 1.233, 95\% CI 0.989 to 1.536, $\mathrm{p}=0.062$ ) and pedestrian (AOR $1.770,95 \%$ CI 1.594 to $1.965, \mathrm{p}<0.001)$ were positively associated with prehospital CPA, whereas bicyclist (AOR 0.779, 95\% CI 0.688 to $0.882, \mathrm{p}<0.001$ ) was negatively associated with prehospital CPA.

Table 3 shows the proportion of patients in CPA at hospital arrival among males and females according to various variables. Compared with that of female sex, the AOR of male sex was greater in patients aged 15-29 years (AOR 1.362, 95\% CI 1.095 to $1.693, \mathrm{p}<0.001$ ), 30-59 years (AOR $1.427,95 \%$ CI 1.217 to $1.673, \mathrm{p}<0.001$ ) and 60-74 years (AOR $1.400,95 \%$ CI 1.202 to $1.630, \mathrm{p}<0.001$ ) among the age groups, and for car driver (AOR 2.249, $95 \%$ CI 1.799 to $2.810, \mathrm{p}<0.001)$ and motorcycle rider (AOR $1.509,95 \%$ CI 1.195 to $1.905, \mathrm{p}<0.001$ ) as types of patients.

Table 4 shows the association between types of traffic crash patients and prehospital CPA in urban or rural areas. In both areas, compared with car driver, back seat passenger and pedestrian were positively associated with prehospital CPA. In contrast, pillion passenger was positively associated with prehospital CPA in rural areas (AOR $1.808,95 \%$ CI 1.204 to $2.716, \mathrm{p}=0.004$ ) but not in urban areas. The time interval from ambulance call to hospital arrival was significantly shorter in urban areas than in 
Table 1 Characteristics of traffic accident patients according to status at hospital arrival

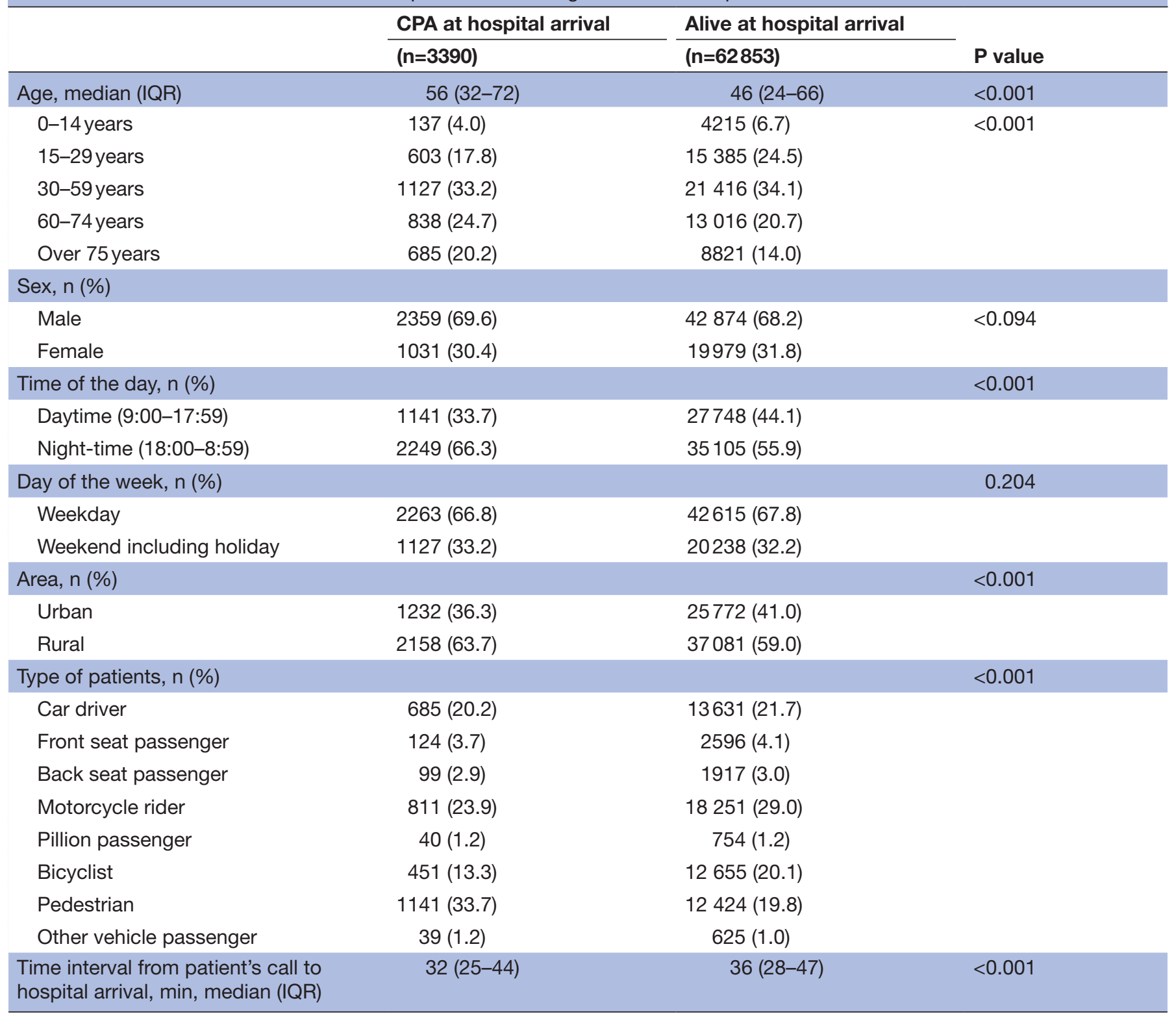

CPA, cardiopulmonary arrest.

rural areas (35 min (IQR: 27-45 min) vs $37 \mathrm{~min}$ (IQR: 28-49 min), $\mathrm{p}<0.001)$.

In a subgroup analysis by age group (online supplementary table 1 ), the OR of male sex was not high in the elderly patients (AOR 1.091, 95\% CI 0.966 to 1.232, $\mathrm{p}=0.162$ ), but it was significantly higher in the young patients (AOR 1.341, 95\% CI 1.201 to $1.498, \mathrm{p}<0.001$ ). The AORs for the other variables were similar between the two groups.

\section{DISCUSSION}

Using data from the JTDB as a large-scale hospital-based trauma registry in Japan, this study revealed that the elderly aged $60-74$ and $\geq 75$ years, night-time, weekend including holiday, rural area and type of patients, such as back seat passenger and pedestrian, were associated with prehospital CPA due to a traffic crash. In addition, this study showed that the type of victim of a traffic crash was different between urban and rural areas. These results provide fundamental information on the actual situation of traffic crashes in prehospital settings and will be of help in planning policies to prevent traffic crashes.

First, this study revealed that the elderly were associated with prehospital CPA due to traffic crash. This result was almost the same as that in our previous report from urban areas $^{6}$ and in other studies. ${ }^{13-15}$ Japan is a super-ageing society, and the number of the elderly aged $\geq 65$ years and those $\geq 80$ years reached 33 million and 9.3 million persons in 2014, respectively. ${ }^{16}$ The population of elderly people will continue to increase worldwide in the future, ${ }^{17}$ 
Table 2 Prehospital factors associated with CPA at hospital arrival among traffic accident patients

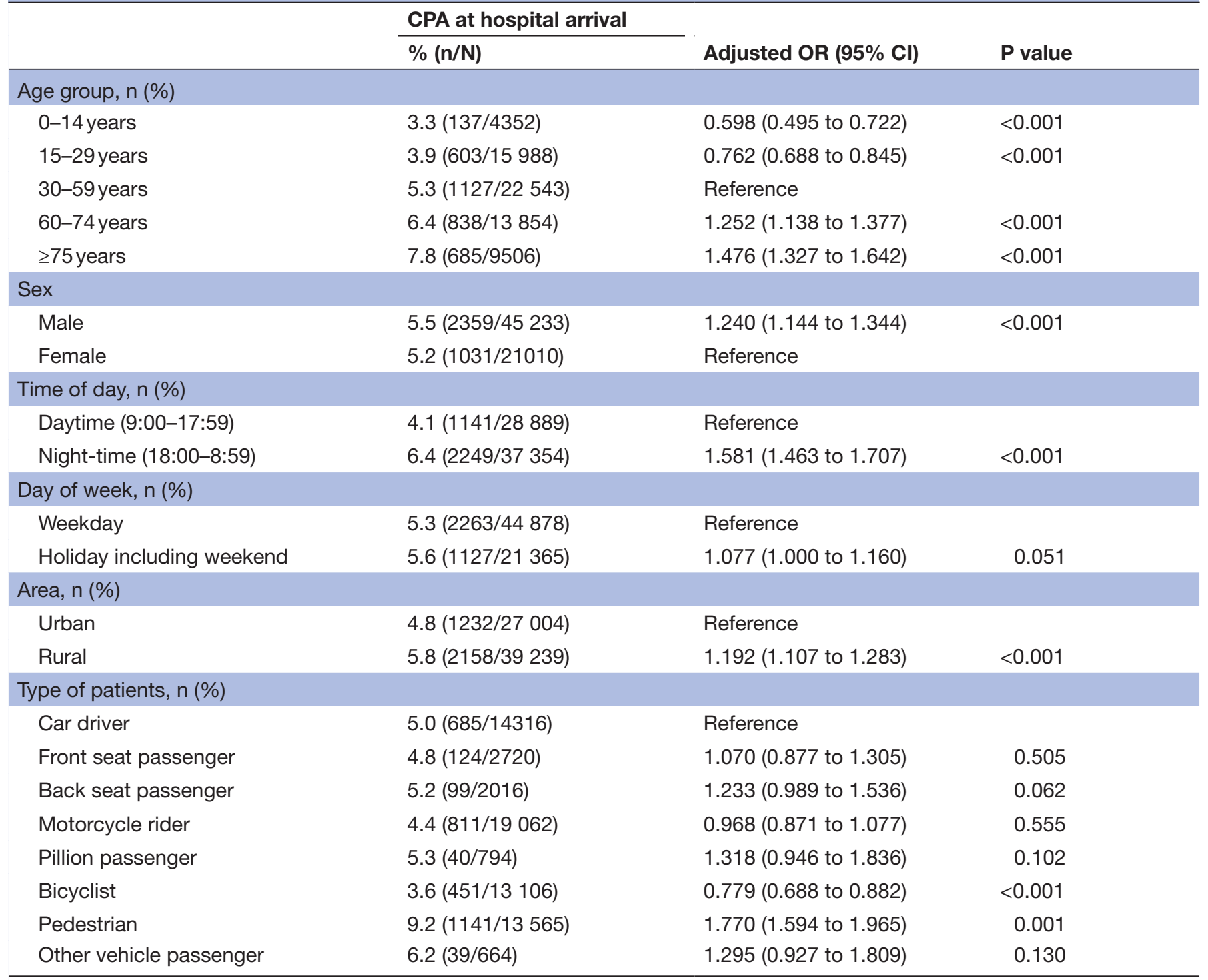

CPA, cardiopulmonary arrest; $\mathrm{n} / \mathrm{N}$, number of fatalities/number of patients.

and the prevention of traffic crashes in this age group is an urgent issue. In addition, the incremental increase in fatal crashes by elderly drivers has recently become a social problem in Japan. An experimental study revealed that awareness and the driving ability of the elderly were more limited compared with those of younger people, ${ }^{18}$ which might lead to more serious consequences among the elderly who cannot respond quickly to avoid a traffic crash. Indeed, Zhang et al reported that the proportion of fatal accidents increased with increasing age even among the elderly aged $\geq 65$ years. ${ }^{19}$ In March 2017, a system to require relinquishment of an elderly person's driver's licence was introduced in Japan if that person has dementia diagnosed by a physician and has reached a certain age.$^{20}$ This could decrease the number of traffic crashes caused by elderly drivers in the future, but it will be necessary to further monitor and assess the effect of the introduction of this system.
Second, this study underscored that night-time and weekend including holiday were associated with prehospital CPA due to traffic crash. Several previous studies showed that the relationship between night-time and traffic crash deaths was similar to ours. ${ }^{2-23}$ Previous studies also revealed that darkness was associated with traffic accident deaths. ${ }^{21-23}$ For example, alcohol drinking, drug abuse and fatigue from driving at night were associated with traffic accident deaths. ${ }^{24-26}$ Because the traffic volume is lower at night and drivers might tend to drive carelessly, such as by speeding or ignoring traffic lights, night-time might be associated with increased prehospital deaths due to traffic accidents. For bicycles, dangerous riding without lights and riding after drinking might also be associated with prehospital deaths due to traffic accidents in the dark. ${ }^{27}$ Therefore, illumination for bicyclists and pedestrians, especially for elderly pedestrians, on dark roads would help to decrease traffic 
Table 3 ORs of males versus females for CPA at hospital arrival after a traffic accident

\begin{tabular}{|c|c|c|c|c|c|c|}
\hline & $\begin{array}{l}\text { CPA at hospital } \\
\text { arrival in male }\end{array}$ & $\begin{array}{l}\text { CPA at hospital } \\
\text { arrival in female }\end{array}$ & Crude OR & $P$ value & Adjusted OR* & \\
\hline & $\%(n / N)$ & $\%(n / N)$ & (Reference; female) & & (Reference; female) & $P$ value \\
\hline $0-14$ years & $2.6(80 / 3032)$ & $4.3(57 / 1320)$ & $0.600(0.425$ to 0.849$)$ & 0.004 & $0.666(0.468$ to 0.947$)$ & 0.024 \\
\hline 15-29years & $4.0(490 / 12.246)$ & $3.0(113 / 3742)$ & $1.339(1.087$ to 1.648$)$ & $<0.001$ & 1.362 (1.095 to 1.693$)$ & $<0.001$ \\
\hline 30-59years & $5.4(915 / 16$ 883) & $3.7(212 / 5660)$ & $1.473(1.264$ to 1.715$)$ & $<0.001$ & 1.427 (1.217 to 1.673$)$ & $<0.001$ \\
\hline$\geq 75$ years & $6.4(323 / 5029)$ & $8.1(362 / 4477)$ & 0.780 (0.668 to 0.912$)$ & 0.002 & $0.986(0.832$ to 1.168$)$ & 0.870 \\
\hline Time of day, n (\%) & & & & & & \\
\hline Daytime (9:00-17:59) & $4.0(711 / 17$ 976) & $3.9(430 / 10$ 913) & $1.004(0.889$ to 1.134$)$ & 0.949 & $1.179(1.034$ to 1.345$)$ & 0.014 \\
\hline $\begin{array}{l}\text { Night-time (18:00- } \\
8: 59)\end{array}$ & $6.0(1648 / 27$ 257) & $6.0(601 / 10$ 097) & 1.017 (0.923 to 1.1120$)$ & 0.735 & $1.274(1.150$ to 1.411$)$ & $<0.001$ \\
\hline Area, n (\%) & & & & & & \\
\hline Urban & 4.7 (914/19 369) & $4.2(318 / 7635)$ & $1.140(1.000$ to 1.298$)$ & 0.050 & 1.223 (1.108 to 1.350$)$ & $<0.001$ \\
\hline Rural & $5.6(1445 / 25864)$ & $5.3(713 / 13$ 375) & $1.051(0.958$ to 1.152$)$ & 0.292 & 1.264 (1.099 to 1.4539$)$ & 0.001 \\
\hline Type of patients, n (\%) & & & & & & \\
\hline Car driver & $5.6(591 / 10521)$ & $2.5(94 / 3795)$ & 2.343 (1.879 to 2.923$)$ & $<0.001$ & 2.249 (1.799 to 2.810$)$ & $<0.001$ \\
\hline Front seat passenger & $4.2(47 / 1129)$ & $4.8(77 / 1591)$ & 0.854 (0.589 to 1.238$)$ & 0.405 & $0.870(0.585$ to 1.293$)$ & 0.490 \\
\hline Back seat passenger & $5.6(48 / 854)$ & $4.4(51 / 1162)$ & $1.297(0.866$ to 1.944$)$ & 0.207 & 1.30480 .846 to 2.010 ) & 0.229 \\
\hline Motorcycle rider & $4.5(724 / 16$ 170) & $3.0(87 / 2892)$ & 1.511 (1.206 to 1.894$)$ & $<0.001$ & 1.509 (1.195 to 1.905$)$ & 0.001 \\
\hline
\end{tabular}

*When assessing one variable, we adjusted other variables listed in this table.

$\mathrm{CPA}$, cardiopulmonary arrest; $\mathrm{n} / \mathrm{N}$, number of fatalities/number of patients.

accidents at night. Anowar et al reported that the number of fatal traffic crashes on public holidays was greater than that on ordinary weekends. ${ }^{28}$ In our study, increments in the opportunity to undertake long-distance travel using expressways on the weekend and holidays and drivers' fatigue from long driving times or leisure activities could have contributed to more serious consequences among the patients with traffic crashes at these times. Therefore, it is also expected that prehospital CPA due to traffic crash on weekends and holidays will be reduced with the progress made by information technology to support drivers and automatic driving technology. ${ }^{29}$

Third, back seat passengers were also associated with prehospital CPA due to traffic crash. In Japan, the prevalence of seatbelt wearing among back seat passengers was lower than that among car drivers and front seat passengers ${ }^{30}$ which could have contributed to the association of prehospital CPA due to traffic crash with back seat passengers. Pedestrians were also associated with prehospital CPA due to traffic crash as other previous studies have shown. ${ }^{631-33}$ Although it is possible to reduce the severity of injury due to traffic crash among car drivers by improving car safety performance, it is very difficult to reduce the severity of injury for pedestrians. Therefore, the development and introduction of an automobile collision avoidance system ${ }^{29}$ and an air bag system for pedestrians ${ }^{34}$ could lead to an improved prognosis for pedestrians in traffic crashes in the future.

The AOR of male sex versus female sex was greater in patients aged 15-74 years, car drivers and motorcycle riders. A previous study revealed that the proportion of traffic violations and serious traffic accidents was significantly higher in males than in females. ${ }^{35}$ As well, the proportion of men who are driving for work, such as truck drivers and taxi drivers, is overwhelmingly higher compared with that of women. ${ }^{36}$ Thus, these factors might also be related to the high proportion of CPA at hospital 
Table 4 ORs of CPA at hospital arrival according to the type of traffic accident patient by urban or rural area

\begin{tabular}{|c|c|c|c|}
\hline \multirow[b]{2}{*}{ Area } & CPA at hospital arrival & \multirow[b]{2}{*}{ Adjusted OR* (95\% Cl) } & \multirow[b]{2}{*}{$P$ value } \\
\hline & $\%(n / N)$ & & \\
\hline \multicolumn{4}{|l|}{ Urban } \\
\hline Front seat passenger & $3.4(26 / 771)$ & 0.766 (0.503 to 1.166$)$ & 0.214 \\
\hline Back seat passenger & $5.0(30 / 603)$ & $1.186(0.795$ to 1.769$)$ & 0.404 \\
\hline Pillion passenger & $3.2(13 / 405)$ & 0.789 (0.443 to 1.403$)$ & 0.419 \\
\hline Bicyclist & $2.9(174 / 6052)$ & $0.612(0.495$ to 0.758$)$ & $<0.001$ \\
\hline Pedestrian & $7.3(393 / 5365)$ & 1.455 (1.206 to 1.756$)$ & $<0.001$ \\
\hline Other vehicle passenger & $4.0(12 / 294)$ & $0.884(0.487$ to 1.607$)$ & 0.687 \\
\hline \multicolumn{4}{|l|}{ Rural } \\
\hline Motorcycle rider & $4.3(410 / 9548)$ & 0.967 (0.845 to 1.107$)$ & 0.630 \\
\hline Pillion passenger & $6.9(27 / 389)$ & $1.808(1.204$ to 2.716$)$ & 0.004 \\
\hline Bicyclist & $3.9(277 / 7054)$ & 0.882 (0.756 to 1.028$)$ & 0.108 \\
\hline Pedestrian & $9.1(748 / 8200)$ & 1.916 (1.689 to 2.172$)$ & $<0.001$ \\
\hline Other vehicle passenger & $7.3(27 / 370)$ & 1.578 (1.053 to 2.366$)$ & 0.027 \\
\hline
\end{tabular}

${ }^{*}$ Adjusted for age, sex, time of day and day of the week.

$\mathrm{CPA}$, cardiopulmonary arrest; $\mathrm{n} / \mathrm{N}$, number of fatalities/number of patients.

arrival among males aged $15-74$ years and those who are car drivers and motorcycle riders.

Finally, rural areas were more associated with prehospital CPA due to traffic crash than were urban areas in Japan. Li et alin Taiwan also demonstrated that the proportion of prehospital traffic crash deaths was higher in rural areas than in urban areas, which was explained by the lower proportion of those wearing a seatbelt or helmet, motorcycle riders and the higher incidence of highway crashes in rural areas than in urban areas. ${ }^{37}$ Because there are fewer emergency medical centres in Japan per unit area in rural than in urban areas ${ }^{38}$ and ambulances need to transport traffic crash patients to distant emergency hospitals following an accident, rural areas might be associated with the poor prognosis of patients in a traffic crash. Indeed, the time interval from ambulance call to hospital arrival in rural areas was longer than that in urban areas in this study. The further introduction of medical helicopters and emergency life-saving technicians who can treat patients with trauma in rural areas might reduce the incidence of prehospital CPA due to traffic crash. Pillion passengers were also associated with prehospital CPA due to traffic crash in rural areas from a subgroup analysis divided between urban and rural areas. Although roads are crowded and motorcycle riders cannot speed up in urban areas, they can easily drive quickly in rural areas as the roads are less crowded. If unprotected pillion passengers are suddenly involved in a traffic crash, there are few mechanical devices other than a helmet to reduce their severity of injury. These factors could partially explain why pillion passengers were associated with prehospital CPA due to traffic crash in rural areas. The prevention of motorcycle traffic accidents would appear to be more important in rural areas, and therefore, it might be necessary to crack down more seriously against violations such as not wearing a helmet in rural areas than in urban areas.

\section{Limitations}

This study has some inherent limitations. First, this study was not a population-based observation regarding traffic injuries but was conducted based on a multicentre hospital-based trauma registry. Therefore, there might be differences in the results between the participating and non-participating hospitals. Second, information on crash situations such as highway type, weather, road conditions and safety devices such as helmets and seatbelts was not obtained for the JTDB registry. Third, we excluded $24.6 \%$ (21 688/87 931) of the traffic crash patients because of missing data needed for our analysis. However, patient characteristics were similar between the included and excluded patients, and we believe that the influence of patient exclusion from this study would be small (online supplementary table 2). Fourth, the aim of this study was to assess the factors associated with fatal injury such as CPA at the scene due to a traffic accident. However, as the information on CPA at the scene was not obtained in the JTDB registry, we focused on the patients in CPA on 
hospital arrival in our study. Therefore, some patients in CPA at the scene achieved return of spontaneous circulation at hospital arrival and were misclassified as survivors at hospital arrival in our study. However, a previous study revealed that the proportion of traffic accident patients in CPA with ROSC before hospital arrival was only $3 \%$ in Japan, ${ }^{39}$ and thus, this influence would be small. Fifth, because no data were recorded on driver's age and sex in the JTDB, we could not analyse the influence of these factors on the occurrence of prehospital CPA due to traffic crash. Finally, as this study was a retrospective observational study, there might be unknown confounding factors that influence the relationship between the examined factors and prehospital CPA due to traffic crashes.

\section{CONCLUSION}

From an analysis of the data in a nationwide multicentre hospital-based trauma registry in Japan, we showed that the elderly, weekends including holidays, night-time, and back seat passengers and pedestrians as types of patients were associated with prehospital CPA due to a traffic crash. In addition, the type of patients associated with prehospital CPA due to a traffic crash differed between urban and rural areas. These fundamental data may be of help in reducing and preventing traffic crash deaths in the future.

\section{Author affiliations}

${ }^{1}$ Department of Traumatology and Acute Critical Medicine, Osaka University Graduate School of Medicine, Suita, Japan

${ }^{2}$ Division of Environmental Medicine and Population Sciences, Department of Social and Environmental Medicine, Osaka University Graduate School of Medicine, Suita, Japan

${ }^{3}$ Department of Food Science, Faculty of Home Economics, Otsuma Women's University, Tokyo, Japan

${ }^{4}$ Department of Health and Sport Sciences, Osaka University Graduate School of

Medicine, Medicine for Sports and Performing Arts, Suita, Japan

${ }^{5}$ Emergency and Critical Care Center, Osaka Police Hospital, Osaka, Japan

${ }^{6}$ Department of Emergency Medicine, Kyoto Prefectural University of Medicine, Kyoto, Japan

${ }^{7}$ Health Services, Kyoto University, Kyoto, Japan

${ }^{8}$ Intensive Care Unit, Department of Anesthesiology, The Jikei University School of Medicine, Tokyo, Japan

Acknowledgements The authors thank the emergency medical service personnel, nurses and emergency physicians who participated in the JTDB. This article was supported by the Clinical Investigator's Research Project in the Osaka University Graduate School of Medicine.

Contributors YK, KK, JS and TM performed statistical analysis of the collected data. YK, TeK, TH, TM, TaK, JI, YN and TS interpreted the data. YK, TeK, TH, YN and TS prepared the manuscript. All authors read and approved this version of the manuscript for submission.

Funding This study was supported by research funding from ZENKYOREN (the National Mutual Insurance Federation of Agricultural Cooperatives).

Competing interests None declared.

Patient consent for publication Not required.

Ethics approval This study was approved by the ethics committee of the Osaka University Graduate School of Medicine (№: 16260).

Provenance and peer review Not commissioned; externally peer reviewed.

Data sharing statement № additional data are available.
Open access This is an open access article distributed in accordance with the Creative Commons Attribution Non Commercial (CC BY-NC 4.0) license, which permits others to distribute, remix, adapt, build upon this work non-commercially, and license their derivative works on different terms, provided the original work is properly cited, appropriate credit is given, any changes made indicated, and the use is non-commercial. See: http://creativecommons.org/licenses/by-nc/4.0/.

\section{REFERENCES}

1. e-stat. Annual report of national police agency in 2016. http://www. e-stat.go.jp/SG1/estat/List.do?lid=000001174329 (Accessed 13 Jun 2018).

2. Organization for Economic Cooperation and Development. Road safety annual report. 2016 http://www.oecd-ilibrary.org/transport/ road-safety-annual-report-2016_irtad-2016-en (Accessed 13 Jun 2018).

3. World Health Organization. Global status report on road safety. http://who.int/violence_injury_prevention/road_safety_status/2015/ en/ (Accessed 13 Jun 2018).

4. National Police Agency. Statistics of traffic accidents in Japan [in Japanese]. http://www.e-stat.go.jp/SG1/estat/List.do?lid= 000001168544 (Accessed 13 Jun 2018).

5. Roudsari BS, Nathens AB, Cameron $P$, et al. International comparison of prehospital trauma care systems. Injury 2007;38:993-1000.

6. Katayama Y, Kitamura T, Kiyohara K, et al. Factors associated with prehospital death among traffic accident patients in Osaka City, Japan: a population-based study. Traffic Inj Prev 2018;19:49-53.

7. J. apan Trauma Care and ResearchJapan trauma data bank annual report 2011-2015. https://www.jtcr-jatec.org/traumabank/dataroom/ data/JTDB2016.pdf (Accessed 13 Jun 2018).

8. Ministry of Internal Affairs and Communications of Japan. Local autonomy law. http://www.soumu.go.jp/main_content/000292921. pdf (Accessed 13 Jun 2018).

9. Yumoto T, Mitsuhashi T, Yamakawa Y, et al. Impact of cushing's sign in the prehospital setting on predicting the need for immediate neurosurgical intervention in trauma patients: a nationwide retrospective observational study. Scand J Trauma Resusc Emerg Med 2016;24:147.

10. Shoko T, Shiraishi A, Kaji M, et al. Effect of pre-existing medical conditions on in-hospital mortality: analysis of 20,257 trauma patients in Japan. J Am Coll Surg 2010;211:338-46.

11. Nakada TA, Nakao S, Mizushima Y, et al. Association between male sex and increased mortality after falls. Acad Emerg Med 2015;22:708-13.

12. von Elm E, Altman DG, Egger M, et al. The Strengthening the Reporting of Observational Studies in Epidemiology (STROBE) statement: guidelines for reporting observational studies. J Clin Epidemiol 2008;61:344-9.

13. Bouaoun L, Haddak MM, Amoros E. Road crash fatality rates in France: a comparison of road user types, taking account of travel practices. Accid Anal Prev 2015;75:217-25.

14. Loo BPY, Tsui KL. Pedestrian injuries in an ageing society: insights from hospital trauma registry. J Trauma 2009;66:1196-201.

15. Dunbar $\mathrm{G}$. The relative risk of nearside accidents is high for the youngest and oldest pedestrians. Accid Anal Prev 2012;45:517-21.

16. Office C. Government of Japan. White paper of aging society in Japan [in Japanese]. 2016 http://www8.cao.go.jp/kourei/whitepaper/ w-2016/gaiyou/pdf/1s1s.pdf (Accessed 13 Jun 2018).

17. World Health Organization. World report on ageing and health. 2015 http://apps.who.int/iris/bitstream/10665/186463/1/9789240694811 eng.pdf?ua=1 (accessed 13 Jun 2018).

18. Morita K, Sekine M, Okada T, et al. Experimental study on recognition and operation characteristics of elderly drivers [in Japanese]. Research Presentation Summary of Traffic Safety and Environmental Laboratory 2005:93-8.

19. Zhang J, Lindsay J, Clarke K, et al. Factors affecting the severity of motor vehicle traffic crashes involving elderly drivers in Ontario. Accid Anal Prev 2000;32:117-25.

20. National Police Agency. White paper of police [in Japanese]. 2004 https://www.npa.go.jp/hakusyo/h17/hakusho/h17/html/G1030000. html (Accessed 13 Jun 2018).

21. Rodgers GB. Bicyclist deaths and fatality risk patterns. Accid Anal Prev 1995;27:215-23.

22. Damsere-Derry J, Ebel BE, Mock CN, et al. Pedestrians' injury patterns in Ghana. Accid Anal Prev 2010;42:1080-8.

23. Stone M, Broughton J. Getting off your bike: cycling accidents in great Britain in 1990-1999. Accid Anal Prev 2003;35:549-56.

24. Keall MD, Frith WJ, Patterson TL. The contribution of alcohol to night time crash risk and other risks of night driving. Accid Anal Prev 2005;37:816-24. 
25. Rice TM, Peek-Asa C, Kraus JF. Nighttime driving, passenger transport, and injury crash rates of young drivers. Inj Prev 2003;9:245-50.

26. Rzeznikiewiz D, Tamim H, Macpherson AK. Risk of death in crashes on ontario's highways. BMC Public Health 2012;12:1125.

27. National Police Agency of Japan. Report of traffic crackdown for cyclist 2016 [in Japanese]. https://www.npa.go.jp/koutsuu/kikaku/ bicycle/pdf/3_torishimari.pdf (Accessed at 03 Oct 2018).

28. Anowar S, Yasmin S, Tay R. Comparison of crashes during public holidays and regular weekends. Accid Anal Prev 2013;51:93-7.

29. National Agency for Automotive Safety and Victim's Aid. Autonomous emergency braking system [in Japanese]. http://www. nasva.go.jp/mamoru/active_safety_search/collision_avoidance_ system.html (Accessed 13 Jun 2018).

30. National Police Agency in Japan and Japan Automobile Federation National Survey about wearing seatbelts. 2017 https://www.npa.go. jp/koutsuu/kikaku/seatbelt/npa_jaf_research29.pdf (Accessed 13 Jun 2018).

31. Ameratunga S, Hijar M, Norton R. Road-traffic injuries: confronting disparities to address a global-health problem. Lancet 2006;367:1533-40.

32. Hyder AA, Peden M. Inequality and road-traffic injuries: call for action. Lancet 2003;362:2034-5.
33. Kröyer HR. The relation between speed environment, age and injury outcome for bicyclists struck by a motorized vehicle - a comparison with pedestrians. Accid Anal Prev 2015;76:57-63.

34. Corporation S. Air bag for pedestrians [in Japanese]. https://www. subaru.jp/impreza/impreza/safety/safety3.html (Accessed 13 Jun 2018).

35. Zhang G, Yau KK, Chen G. Risk factors associated with traffic violations and accident severity in China. Accid Anal Prev 2013;59:18-25.

36. Cabinet Office, Government of Japan. The White paper of road traffic safety in 2017 [in Japanese]. http://www8.cao.go.jp/koutu/taisaku/ h29kou_haku/zenbun/genkyo/h1/h1b1s2_3.html (Accessed 20 Sep 2018).

37. Li MD, Doong JL, Chang KK, et al. Differences in urban and rural accident characteristics and medical service utilization for traffic fatalities in less-motorized societies. J Safety Res 2008;39:623-30.

38. Ministry of Health, Labour and Welfare of Japan. Critical care center survey [in Japanese]. 2012 http://www.mhlw.go.jp/stf/shingi/ 2r9852000002xuhe-att/2r9852000002xumn.pdf (Accessed 13 Jun 2018).

39. Kitamura T, Kiyohara K, Sakai T, et al. Epidemiology and outcome of adult out-of-hospital cardiac arrest of non-cardiac origin in Osaka: a population-based study. BMJ Open 2014;4:e006462. 